Research

\title{
A sustainable model for small towns and peripheral communities: converging elements and qualitative analysis
}

\author{
Giovanni Colombo ${ }^{1,2}$ \\ Received: 27 April 2021 / Accepted: 3 August 2021 \\ Published online: 14 September 2021 \\ (c) The Author(s) 2021 OPEN
}

\begin{abstract}
The paper's conceptual framework is the United Nations Agenda 2030 and the long-term Sustainable Development Goals. Scientific work on environmental issues has underlined the urgency and profoundness of the transformations needed to achieve the COP21 global warming thresholds in the short time left. Despite the systemic character of sustainability, most suggested innovation policies do not consider the advantages of an integrated view of environmental and social issues. The paper explores this possibility by analysing the chances of minor centres (small towns and peripheral communities) to combine these challenges in sustainable development models. Transformative innovation steps inspired by the responsible innovation approach are vital instruments to reach that goal. The paper's conjecture about the minor centres is supported by analysing three main courses in the sustainability route: the conversion to renewable energy, the circular economy, and the digitalisation process. The analysis offers innovation hints for the responsible development of plans such as the Next Generation EU, launched to support Europe's economic revival in the post-pandemic phase.
\end{abstract}

Keywords Responsible approach to Sustainable Development · Small Towns and Peripheral Centres · Technological Advances and Digitalisation

\section{Introduction}

During the last decade, global organisations have matured a growing sensibility on the environmental decay and social inequalities in the various forms they threaten the planet's life. The UN's Sustainable Development Goals [1] collect all these ethical burdens under the sustainability concept. European innovation policies are resolutely focusing on these issues, and the 2020 Report on sustainability [2] is an eloquent summary of the achievements and limits registered until now. The Plan Next Generation EU recently launched to revitalise the Union's economy in the post-COVID era [3] is a fundamental step to improving the Union integration through solidarity principles and shared financial tools: the essential ingredients to face those challenging issues.

The pandemic has roused in our conscience the sense of human limits, the awareness of social contradictions, and the confidence in the essential role of scientific knowledge in facing adverse circumstances. Thanks to the acquired sensibilities, the post-pandemic era can become a unique opportunity to face the ethical dilemma of dealing jointly with environmental and societal issues.

The above-intertwined problems are very complex to tackle in that they touch several human agency dimensions altogether. The extensive scientific work produced after the Paris' COP 21 conference on climate change offers several hints to discuss this

Giovanni Colombo, giovanni.colombo3@gmail.com | ${ }^{1}$ Former CTO of Telecom Italia Lab and Director of Istituto Superiore Mario Boella, Turin, Italy. ${ }^{2}$ Former member of the Governing Board of the EIT; External teacher at Politecnico di Torino until 2018, Turin, Italy. 
integration challenge. The development narratives of the Intergovernmental Panel on Climate Change (IPCC) merge socioeconomic aspects, the associated climate policies, and the resulting evolution of the greenhouse gases concentration. For instance, the warming threshold of 1.5 centigrade degrees $(1.5 \mathrm{~cd})$ calls for very challenging measures to be (possibly) achieved by 2100 . The measures should ground on low energy consumption, fair food demand per capita, improved energy and resource efficiency, and responsible land use. IPCC assigns the same importance to social issues like economic redistribution, environmental consciousness, behavioural coherence, cooperation, and the citizens' participatory attitude [4, p. 109-114, 452-462]. These objectives are far from being fulfilled by the current economic progression and the restless growth of economic inequalities within and between nations, affecting both developed and emergent economies [5, p. 42-44, 6].

One of the limits of the after-Paris elaborations is that the efforts addressing environmental health and those polarised to social wellbeing seem to proceed independently. This approach may weaken the overall action because it fails to leverage the cross-fertilisation effect that may arise (or be intentionally induced) between the two aims. Figure 1 summarises the mechanisms through which social and environmental conditions can benefit from each other along a positive loop. For instance, the unfair distribution of wealth is not only a social failure per se but a significant threat to environmental stability. In fact, political measures ensuring the progressivity of taxation, the universality of education and health care and dignified jobs [5, ch.5.2, 5.4] favour responsible citizens' behaviour and conscious attention to common goods: the essential ingredients for any successful environmental policy [7].

The core research question addressed in these pages is the possibility to integrate environmental health and social wellbeing purposes through the responsible use of the transformative potentials of technology. More precisely, the paper aims to show that the renaissance of small towns and peripheral communities (for short: minor centres) can generate new socioeconomic models to unravel some sustainability dilemmas. The elaboration proceeds through an integrated analysis of present issues driven by a methodological approach based on responsible innovation principles. The idea is to outline some policy directions consistent with the above conjecture. The research has a qualitative character. The development of more solid and possibly quantitative arguments is in the research plans of the author. However, due to the ethical spirit of the arguments, non-measurable values represent a crucial constituent of the discourse.

In fact, the sustainability aim situates our moral responsibility on a time dimension where we must safeguard future generations' capacity to fulfil the duty of building up their genuine humanity, as Hans Jonas underlined in [8, ch.2 IV, 3-4]. This capacity concerns the physical and cultural conditions to be preserved, including, first of all, the essential ingredients for human existence. It applies naturally to the present situation so that we need to preserve the totality of conditions we deem necessary for a good life, as we see it now. The natural (nonhuman) dimensions belong to the responsibility discourse, and its vulnerability calls for environmental ethics $[8, \mathrm{ch} .1, \mathrm{III}, 1]$, [9, p. 41]. The outer nature can be seen as a part of the physical, cultural and aesthetic essence of humans (anthropocentrism) [10] or as a genuine other having an intrinsic, non-monetarist value (deep ecology). Regardless of this philosophical distinction, preserving the natural dimension and biodiversity is a moral duty to be fulfilled against the continuous and fierce erosion it undergoes from human activities. The above obligations represent a categorical imperative in the Kantian sense and prevent us from threatening that capacity. The ethics of responsibility is, in fact, based on the evaluation of the expected consequences of our actions [11, p. 81-82].

Fig. 1 Sustainability aims, an integrated view

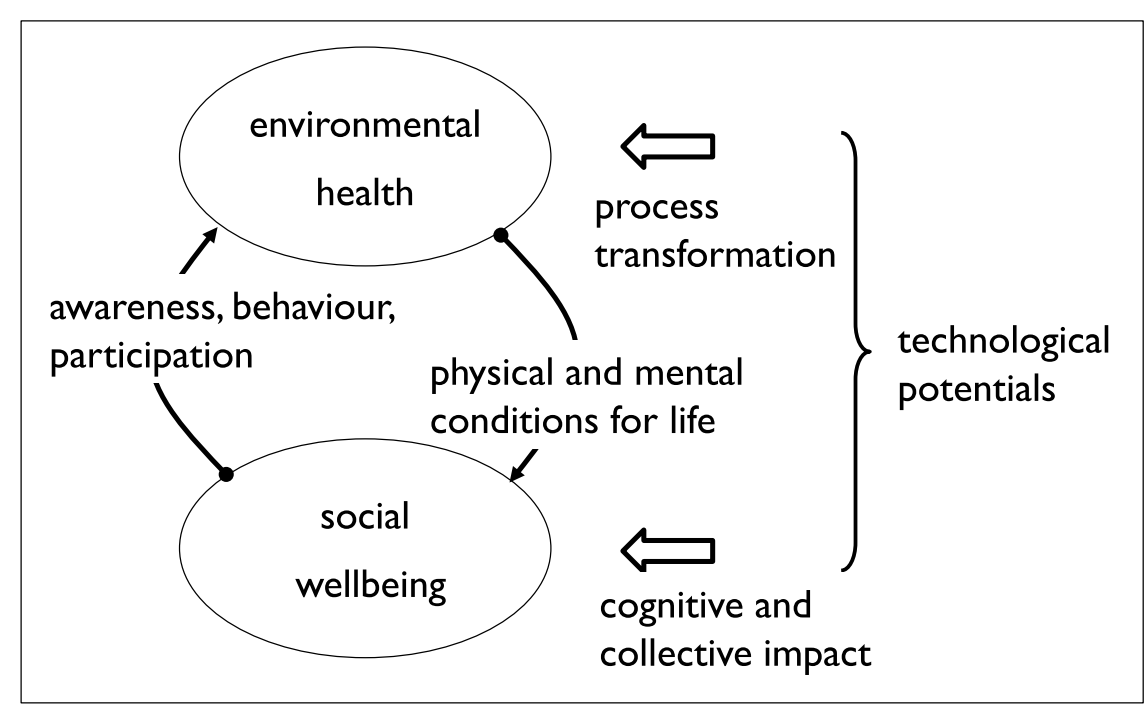


Section 2 describes the methodological approach inspiring the subsequent arguments and highlights the connection with state of the art about sustainability challenges. On this background, Sect. 3 discusses some practical cases and proposes the policy directions that integrate environmental and social requirements in the minor centres' renaissance perspective. The fourth section combines these policy hints and draws some concluding remarks.

\section{Methodology}

An effective way to discuss the sustainability issues is to adopt the responsibility principles recently elaborated about the innovation policies and their critical role in economic and social evolution [12, p. 26-48]. The European initiative named "Responsible Research and Innovation" [13, p. 152-168] addresses the same concepts with a more applicative approach.

The seminal concepts developed in [14, p. 1568-1580] can help face sustainability issues through a responsible innovation approach. It proposes four methodological criteria (dimensions) that should characterise any innovation action. The anticipatory dimension is the most direct implementation of the ethics of the consequences. It tries to answer the "what-if" question associated with the impact of the innovation action on the sustainability-sensitive process under exam. The answer lies in historical data about the process behaviour and some representation of the causal mechanisms driving its evolution. Predicting the action's impact is an arduous exercise due to the complexity of the dynamics blending social, environmental and technical aspects. The consistency with the innovation aims requires that the innovation action is defined from a thorough analysis of the various options available and take charge of the contextual conditions where it operates (reflexivity dimension). Also, a responsible innovation lies in a diffuse practice of informed participation of the involved actors throughout the action (inclusion dimension). Finally, the nonstationary and unpredictable nature of the above processes requires that the innovation scheme react suitably to changing circumstances (responsiveness dimension). The above criteria apply to a vast spectrum of sustainability cases. For instance, they offer an ethical skeleton for the mitigation issues (as in this paper) and adaptation issues, like in [15, p. 41-62], where policy criteria base on anticipatory planning, adaptation to change, awareness and participation are essential methodological instruments.

In recent decades, the effects of our irresponsible development choices have become increasingly evident. We have gained significant knowledge about the progression and persistence of the current drawbacks. Unfortunately, this is insufficient to improve our anticipatory capability because the effects of anthropic changes follow cumulative patterns like depletion of natural resources and increase of greenhouse gases and end-products. This circumstance makes any innovative discontinuity an unprecedented perturbation of a complex process, whose effects can hardly be bridled in consolidated models [8, ch1, III, 1].

The environmental status, together with the prediction uncertainties, led the scientific community to argue that only prompt and disruptive initiatives can safeguard the human being from exceeding the limits fixed in 2015 to the rise of the planet's average temperature (CoP 21). The IPCC recommends that the peak of carbon dioxide $\left(\mathrm{CO}_{2}\right)$ emissions is reached before 2030 to have a reasonable chance of respecting the $1.5 \mathrm{~cd}$ threshold by 2100 . Even in that circumstance, the risk of failure is all but negligible. Significant uncertainties remain about the accuracy of the "cumulative carbon emission" model used to estimate the effect of the $\mathrm{CO}_{2}$ concentration on global warming. Additional risks are due to the unpredictable contribution to greenhouse gases generated by geophysical factors such as permafrost thawing [4, p. 96-97; 104-107]. Extreme (and perilous) solutions such as carbon capture and storage could be necessary to avoid an excess of the limit's overshoots.

The rough evidence of the environmental and social drawbacks suggests that more reassuring perspectives can be recovered only through urgent and profound actions. These requisites reflect the need to mobilise transformative innovations [16, p. 5-6]. A theoretical framework for transformative policies has been elaborated on the wave of environmental and societal issues [17]. It adopts a broad view of the innovation role, affecting both the policy agenda (to be polarised on social challenges rather than on pure economic growth aims) and the innovation processes (that should involve a variety of actors on the demand side of the production chain and exploit both coded and tacit knowledge). This view reenforces the reflexivity and the inclusion dimensions of the responsible innovation principles [14] significantly.

The requirement for transformative actions is repeatedly stressed in [4, p. 320-331], where "simultaneous and profound changes in behaviours, economies and societies" are assigned a fundamental role to accelerate mitigation and adaptation policies for sustainability. Recent studies state that facing sustainability issues inevitably leads to transformative policies [18, p. 50-65]. The balance between environmental and social stability is treated in [19] and [20] and discussed at the macroeconomic level (GDP and labour-to-capital interactions) in [21, 22, p. 251-305].

Although the need for discontinuous innovation paradigms is widely recognised, the relevant principles struggle to consolidate in the current practices. Public authorities mainly follow rationalisation approaches strictly mirroring the administrative assignments to elaborate sustainability plans. A responsible and future-proof approach should instead adopt a transformative mindset. The transformation of a harmful process acts on its endogenous mechanisms and challenges the 
boundary dynamics in search for creative and aim-consistent options (reflexivity). Conversely, the simple rationalisation of the same process often leads to contradictory solutions or a "therapeutical rage", reinforcing the adverse effects under scrutiny. The transformative approach naturally magnifies the (positive or negative) effects of an innovative choice.

By taking these results and advice to the hearth, the minor centre's conjecture will be conducted by looking at the economic and social structure of a country like Italy, which is comparable, for the paper's purposes, to that of any other European country. This lucky area of the planet benefits from a stable level of welfare yet characterised by growing social contradictions. European communities are then suited to test the impact of changes that can significantly modify personal and collective habits.

The ground of the following arguments is the geographical distribution of human settlements. This aspect bonds the European countries in a unique configuration [23, p. 58-60]: few, large and densely populated cities; many towns and centres of medium-small dimension still rich of history and traditions; a multitude of scattered and small villages, often located in distressing places, once living on marginal agricultural productions and more recently doomed to abandonment or tourism (two destinies with many traits in common). The factory model grown in the last two centuries has crumbled this multipolar configuration by gathering human resources, infrastructures, services, research and cultural activities in or around the city. The city has evolved as a multifaceted accumulation point by generating a specular depletion of human life in peripheral places. However, the multipolar configuration is still physically and culturally alive, partially thanks to a process of coming back started far before the pandemic and due, in a sense, to the slow but ineluctable erosion of the original factors of the urban polarisation.

Much work has been produced in Italy about marginal areas by the Forum on Inequalities and Diversities [24, p. 173-183]. This paper makes new arguments favouring place-based development and some conjectures for the responsible use of the technologies embedded in the relevant innovation process.

\section{Sustainability and minor centres-critical reading and policy directions}

More and more, technological advances shape our lives and will likely be crucial to defining future societies'life conditions. Technology will then be the most critical source of helpful or harmful impacts. This section considers three technological innovation aspects that mitigate the global warming generated by the anthropogenic emission of greenhouse gases. They offer significant arguments in favour of the minor centres' renaissance. With this mindset, the section will discuss the conversion to renewable energy sources, the reduction of products' lifecycle footprint, the digitalisation impact on processes and behavioural attitudes. The effect of first two aspects (reported in Fig. 2) are often represented through a couple of measurable performance indicators: the carbon and the energy intensity $[25,26]$.

Fig. 2 Carbon and energy intensity

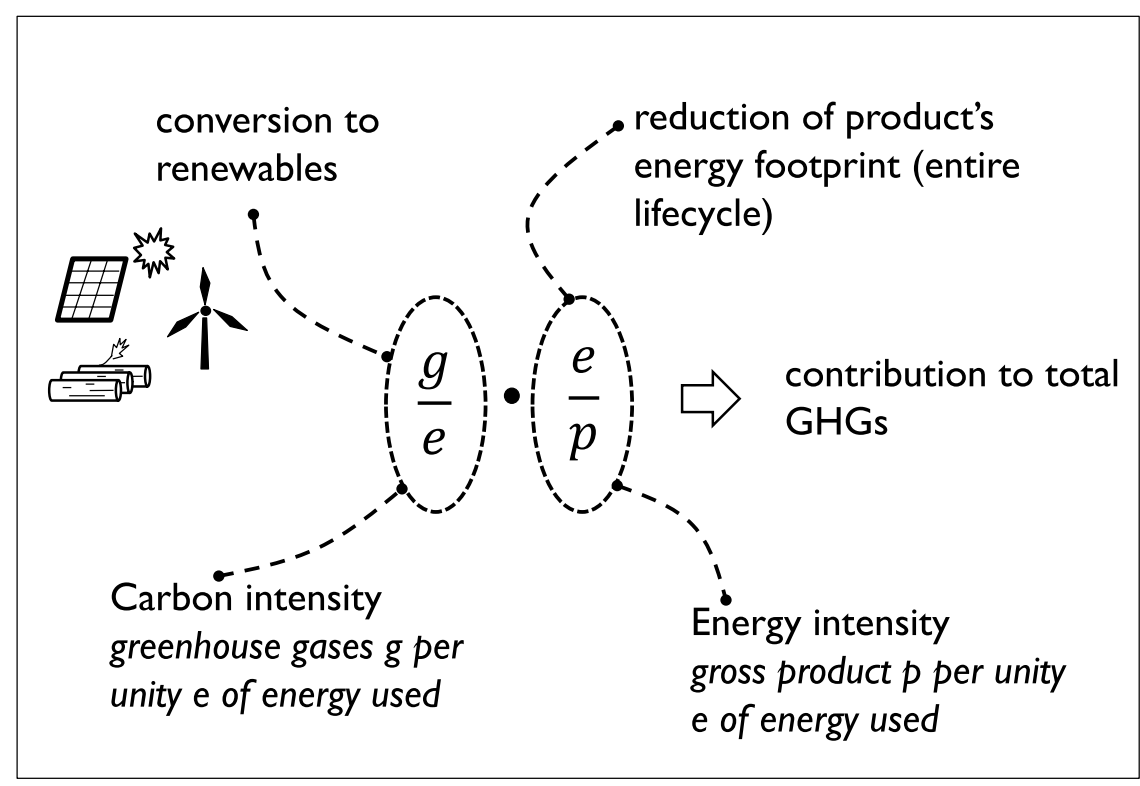




\subsection{Conversion to renewable sources, centralised or local generation?}

The European Union has achieved significant results regarding the environmental targets (20/20/20) fixed for 2020 . The Union has fulfilled the first two targets (20\% reduction of greenhouse gases compared to 1990 levels; $20 \%$ of renewable energy sources in final energy consumption), while the third one ( $20 \%$ of energy efficiency) is just below the aims [27, Appendix 2].

The conversion to renewable energy sources seems to follow the consolidated dualism centralisation-dispersion of the last 15 years: high power wind or solar fields on the one hand, and dispersed, small domestic renewables' plants on the other. Besides the adverse effects on landscape and wildlife habitat [28], the large production fields reproduce the centralised, tree-like distribution topology of the energy networks operated by prominent (primarily public) players. Domestic plants embody a new figure, the "prosumer" (producer/consumer), but give rise to fragmentation of renewable sources and do not exploit the synergies potentially offered by energy-sharing arrangements. Should the coming energy conversion policies reinforce the above dichotomy, the opportunity for a transformative discontinuity involving economic, social and behavioural aspects would disappear.

It is possible to escape from this model continuity by promoting (at least for the household and service sectors) the energy community option. An energy community $(E C)$ groups an ensemble of prosumers who agree on a common mechanism based on the shared storage and the exchange of the individually generated energy. The community has medium-small dimensions (from some units to a few hundred) and acts as a single juridical entity in the interaction with the operators. The stochastic misalignment of the energy production and demand curves is compensated through energy exchanges within the community or between the community and the public networks. The European Union has issued a directive supporting the $E C s$ creation and government [29, art. 22]. Recent studies state that solutions of this nature (typically based on small photovoltaic, wind, hydro and bioenergy plants) can offer remarkable advantages. The growth of $E C s$ reduces the carbon intensity (Fig. 2) and, at the same time, creates, locally, new forms of cooperation-based enterprises [30]. It is perhaps the best way to strengthen the environmental consciousness and produce new and good jobs tied to the system's management, the planning and the control of the process under ecological and economic criteria [31]. Prosumers engaged in the $E C$ will very likely care for the jointly-produced energy: a behavioural aspect avoiding the rebound effect induced by the energy efficiency policies [32].

The social innovation opportunities associated with the EC model have been extensively evaluated in [33, p. 4-5], where indicators such as social capital, social entrepreneurship, and participation in social ventures have been measured in several European cases as proof of the induced benefit. The creation of new ECs has slowed down with the drop of subsidies to renewables. However, the model's relevance could again take off if the initiative coexists with other local ventures [33, p. 18-19].

Fig. 3 Energetic challenge and the effects of technological orientation

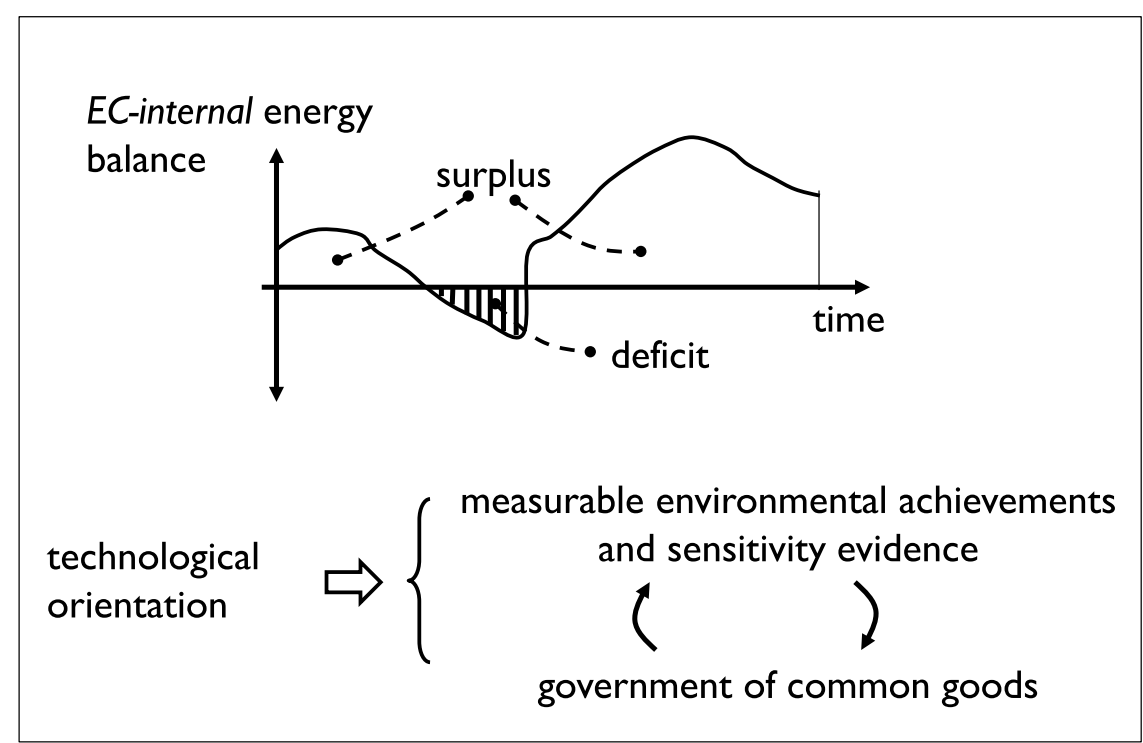


A resolute orientation of the energy conversion policies towards the $E C s$ could affirm a new, place-based socioeconomic model where production and consumption roles collapse in the same household within a community-shared framework of aims and behavioural practices. The evaluation of the achieved sustainability level has to consider the overall advantages potentially induced by this technological orientation (reflexivity). The technical challenge is managing the stochastic characteristics of the $E C$ production and demand curves, for instance, to minimise the internal energy deficits (energy purchased by external suppliers) over time (Fig. 3). Thanks to the system's confinement, this challenge can leverage the measurability of the ecological performance and the sensitivity of the relevant variables (behaviour, control algorithm, economic model). In addition, the $E C$ offers the opportunity to experience a common goods' government: the social control of the entire energy cycle relying on participatory attitudes, technological awareness, reciprocity and trustiness of the community's members.

Politics can promote the creation of ECs through fiscal leverage and the simplification of the community's creation and governance rules [34].

\subsection{Products' lifecycle footprint: technological oligarchy or diffuse knowledge?}

Most innovation plans on goods' production systems address the Industry 4.0 perspective and move in the stream of the existing economic model. The transformation of industrial and biological cycles according to circular economy concepts should deserve equal attention, owing to the radical sustainability policies it can stimulate.

The research supported by the Ellen MacArthur Foundation in 2015 is perhaps the most valuable contribution to the circular economy perspective [35]. The title "Growth Within-A Circular Economy Vision for a Competitive Europe" seems an act of faith in neoliberalism, but the essay subtends radical discontinuities of the existing models in substance. The basic principles of regeneration, sharing, optimisation and reuse recall longstanding environmental movements' positions: a conversion coming from a cultural milieu not adverse to traditional industrialism. European institutions have been working on the circularity concept from the early steps of its formulation. After some initial reluctance to intercept its transformative value [36, 37, p. 4], in March 2020, the Commission issued an Action Plan for circular economy, defined as a crucial premise of climate neutrality [38, p. 16-18]. The plan defines norms, funding and dissemination tools for the member states to realise the circularity principles at all administrative levels: a valuable support for the new paradigm. Even with these disruptive intentions, the plan emphasises that circularity will foster the continent's growth and competitiveness.

These ideological clarifications deserve some comments. It is questionable to assume sustainability as the crucial objective and, simultaneously, to condition it to growth and competitiveness objectives, two aspects on trial as potentially critical sources of environmental and social precarity. This remark is not a tribute to the degrowth but a call to the principle of non-contradiction. If the sustainability aim is assigned a primary urgency position, its implementation should chiefly address environmental and social cohesion perspectives, not necessarily maximising conventional economic indicators.

In line with this view, an anticipatory and reflexive consideration of the circularity concepts should reveal that most of the transformations tied to the circular life cycle of a product occur where the product is used, maintained, repaired, broken up, reused as a whole or in its elements, and finally disposed of in its non-reusable parts if any. All these circularityinduced actions have indubitably to do with the place. If this is true, why not acting intentionally so that these tasks and the knowledge needed to fulfil them become more robust as social values of a new form of the place-based economy?

The economic output and the relevant labour forces connected to the circularity concept can map to the classical distinction between tradable and non-tradable economies. Non-tradable outputs address only the local demand due to their nature (e.g., services or nondurable products subject to unacceptable transport costs). Tradable outputs exceed the local demand and are in general subject to competition rules. The analysis performed in [39] highlights that tradable jobs' wages tend to be higher than those earned by non-tradable jobs. This effect is due to a gap in labour productivity favouring tradable jobs, even though the professional skills of the two economic classes are substantially aligned.

The above bifurcation offers some flexibility to safeguard social stability in a market economy. For instance, in periods of economic downturn, the social robustness of non-tradable sectors can justify partial wage reductions to improve the tradable sectors' productivity (more export, internal devaluation) [40, p. 24-26]. These policies reflect the social market economy principles and have been successfully implemented in some of the most performing European countries during the last financial crisis to mitigate the frictions between social wellbeing and the globalised economy.

It is crucial to recognise the social and environmental value the circular economy can generate locally if adequately exploited. Along the product lifecycle, product management, repairing, reconditioning tasks are strictly relevant to the 
product use (continuous lines in Fig. 4). The cascade reuse of product's parts and recycling tasks are more likely feeding the supply chain (materials and spare parts) and the downstream phases (use and disposal) of other products'lifecycles (dotted lines in Fig. 4). The latter outputs can be more exposed to competitive constraints. All these tasks can re-invent the local economic configuration by exploiting the circular design of the product, based on functions' modularity and the reusability of subsystems and materials. Differently from the in-factory production phases, these local labours are partially shielded from global competition. They mainly fulfil the local demand for keeping alive in all its functionalities, the product in use. They expand the product's life and mitigate its ecological impact: an essential function to be registered as a beneficial effect of the factory's circular design. The product life and the consumer's behaviour are intertwined and ground on cooperation and cohesion values.

Although the circularity approach entirely modifies all the product-cycle phases, the necessary rearrangement could be legitimately led to purely technical and organisational problems addressing the progressive improvement of the energy intensity (Fig. 2) without considering its potential impact on the local dimension [25]. Conversely, the circular model could represent the opportunity to jointly face ecological and social issues through place-based configurations that integrate several sustainability goals.

The circularity concept also holds for biological products. In this field, some exciting aspects are present in the European orientations. The actual Community Agricultural Policy (CAP) has significantly enriched the rural communities' role beyond the pure food production functions. They are now committed to managing natural resources and the cycle of water, guaranteeing animal wellbeing, and protecting the biodiversity of local territories. The Commission has reinforced these purposes in the CAP 2021-2027 [41] and the biodiversity strategy [42, p. 7-9], representing crucial turning points for agricultural practices. The correlation between biological diversity and climate change mitigation is recognised; pesticides should be halved, and organic agriculture extended up to $25 \%$ of the agricultural land by 2030 . These goals will absorb from 30 to $40 \%$ of EU CAP support. A transformative interpretation of the new rural community should naturally adopt the post-Paris proposals about the land policies. Soil (organic) carbon sequestration, for instance, is a natural practice to capture $\mathrm{CO}_{2}$ without producing environmental drawbacks [4, p. 121]. Similar characteristics are present in biochar production, reusing the biological wastes of agricultural and forestry practices. These measures do not compete with food production and realise negative emissions of greenhouse gases by improving soil fertility, water availability and biological diversity [43]. In this sense, they contribute substantially to the mitigation goals (1.5 cd) under different scenarios [44]. The relevant practices can be applied in marginal or less-productive areas (e.g., pre-mountain terrains) that are often subject to land-use changes such as cropland to forestation or pasture [45], and destined to abandonment or subsistence agriculture.

A land use inspired by sustainability ethics, safeguarding a territorial range where the progressive passage from the anthropic to the natural dimension proceeds with the decline of the excess carbon in the atmosphere, could be something beyond the most optimistic expectations. Such a lucky perspective only has realistic chances if the political and social bodies are firmly committed to sustaining the demanding, patient work and the strong motivations requested to

Fig. 4 Circular economy, product lifecycle and the creation of local functions

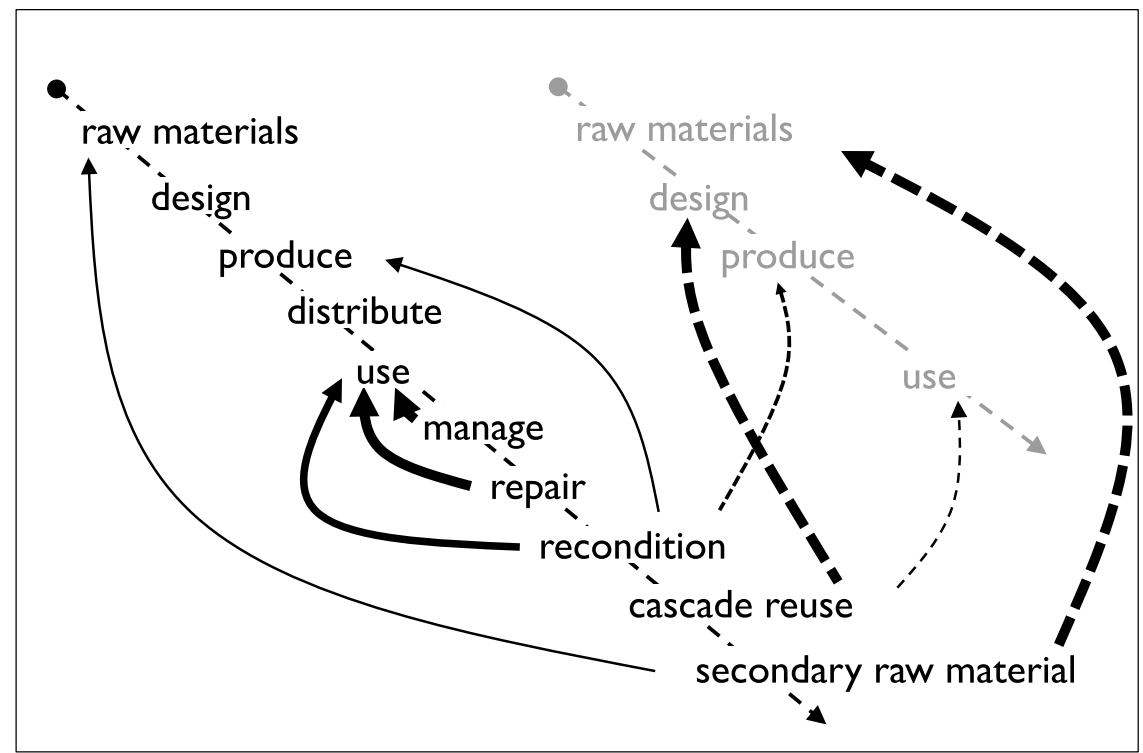


fit this challenging piece of the sustainability puzzle. Once again, the minor centres can become the natural attraction points for these transitional areas.

In addition to the employment perspectives already mentioned, the place-based economy generates several knowledge-intensive jobs raised by the need to represent, measure and tune the new economic and social arrangements. The local community is extending the field of self-determined procedures: a partial re-appropriation of a participatory life. The above professions require high technical knowledge, creativity, manipulation ability and social intelligence, and ground on good jobs, naturally robust to the labour-substitution drift created by the computerisation process [46]. They restore the technological and biological consciousness today sacrificed to the irresponsible practice of throwaway.

Some obstacles may hamper the evolution of the circular economy, as underlined in [47]. The longer products' life implies delayed exploitation of the technological advances and efficiency drop; the discontinuities in the product lifecycle rely on behavioural changes, hence, a sort of user's viscosity can be expected; the new normative framework can be ineffective or contradictory. Some measures could mitigate the potential impact of these adversities. For instance, specific norms could force the supplier to design all the product parts according to backward and forward compatibility criteria to ensure a more systematic technological substitution. Forms of product-service contracts involving the supplier, the user and the local actors throughout the product life should encourage circularity [48]. However, the most significant threat is that social advantages are not valued as essential benefits of circular economy. A fatal error may be framing the overall process in a techno-economic-environmental vest where business is king, and the actual economic models are not challenged. This section has offered some ideas on how to escape from this worthless eventuality.

\subsection{Digitalisation: objective or instrument?}

Digital technologies play a primary role in all life aspects. They offer the functional ground to improve economic and social processes, virtualise the relevant functions and model their behaviour for planning and control purposes. The same techniques affect the cognitive level and the behavioural habits of persons. Digitalised systems replace the routine actions of human work; artificial intelligence and data processing algorithms widen the conceptual abilities in many sectors, such as medical diagnosis, financial orientation and decision support under uncertain conditions. Such great potential encourages the range of our responsibility to grow at least at the same pace of the digital progression.

This section elaborates on some features of digital functions and their responsible use to realise sustainable conditions. A responsible approach in digital innovation should primarily recognise the generic and constitutive power of these techniques. Thanks to its generic nature, any digital function can serve different (often conflicting) intentions. The constitutive character comes into play whenever digitalisation is the only way (the necessary condition) to realise a new mechanism. The improper use of digital functions can create undesirable socioeconomic perturbations. The digital innovation must then be anticipatory and reflexive to stick at the innovation intents (rather than follow technicist impulses) and reactive to redirect the innovated process in the presence of unexpected deviations.

This section discusses these ethical dilemmas concerning a couple of tendencies recently exalted by the need to reduce the inter-personal contacts in the Covid era: the e-commerce of consumer goods and the intelligent working practice. We will see how both affect the local development perspectives.

The goods' distribution/procurement process situates between the production and consumption segments of the product cycle (Sect. 3.2). In the e-commerce model, the digitalisation of the process stages (advertising, product choice, purchasing, payment, transport, delivery and parcel tracking) has been the necessary element to create an entirely new procedure (constitutive character). The resulting process is so rich, comfortable and easy to use that any criticism is unpopular. However, the profoundness of the induced impact urges some ethical concern about this consolidated habit. Here is what happened in the last few decades: the fundamental function of goods' procurement has been gradually deprived of any trace of sociality while the scenery of our consumers' role was seamlessly moved from the renaissance square to the hypermarket as a place of consumerism, to the home door. This progression has extinguished any residual form of physical intermediation between producers and consumers, namely, a good portion of the civic interactions among citizens.

The piece rates raiders, the ready-made food producers, the takeaway workers, the couriers, the sorting and packaging operators of the enormous storage warehouses, are the human representations of increasingly precarious, fragmented and underpaid jobs at the service of the consumer's will to receive at home a product chosen from the planetary shelf of all its possible instances. The fall-out in terms of social alienation is so apparent that nobody can ignore the future we are preparing: the end of shopping points, bookstores, kiosks, restaurants and artisanal labs will anticipate the crisis of hypermarkets with their residual shade of sociality. Never again, the social contract binding goods and economic value 
will maintain its symbolic and collective sense. Rather, it will be a private episode, set up with a simple click, the magic wand of our desires. Concerning the social quality of labour, the gig economy, beyond the lexical novelty, hides concepts such as piece work, exploitation, and work fragmentation that are all but new.

From the pure environmental side, e-commerce may have a sense for entirely virtual products (e.g., movies), but the matter is radically different when physical goods are in play. The e-commerce promise is "you can get hold of what you want, when and where you decide". The choice width, the quickness and the capillarity of delivery are becoming a sort of universal right. The optimisation of the supply and delivery process in terms of costs and environmental impact is somewhat problematic [49]. In any case, the combined effect of the above requirements leads inevitably to harmful impacts on the environment, whatever the optimisation mechanism: high-capacity of logistic centres, immense volumes of goods exchanged, high transport speeds and considerable distances to cover (Fig. 5).

The above social and environmental contradictions have been and still are almost ignored by politicians and innovation agents. However, the present situation offers some chances to exercise our responsiveness attitude from the sustainability perspective.

A good starting point is to register that some alternative models or at least different sensibilities exist. The local production and delivery of agricultural products (zero miles delivery), the attempt to revitalise the proximity stores, and the renaissance of the open-air neighbourhood markets represent a defence line from the overwhelming progression of the "all at my home" paradigm.

Politics should promote these diffuse (though hidden) sensibilities and solicit a public debate about the re-appropriation of a local sociality around the goods procurement process. Some European initiatives support the creation of short supply chains through products' traceability and the reorder of sale points. These initiatives can generate new economic and social configurations, and the minor centres' revitalisation offers a natural ground for this purpose. According to common sense, the potentially induced discontinuity is neither easy nor comfortable: it requires a profound reorientation of personal consciousness and behaviour and a public pursuit to affirm values now threatened by the prevailing hedonistic attitude. The construction of a new state of play could benefit from general measures such as a severe carbon tax on the product's life cycle and the packaging waste charge, anyhow on the horizon.

About the so-called "smart working" practice (which conveys a much broader concept than the prosaic "work at home"), there is no doubt about its effectiveness in virological protection. Nevertheless, some concern may derive from the eventuality that this model is expanded beyond the pandemic, as someone considers inevitable, and others even beneficial. The homework discloses a series of contradictions. It promises greater freedom in the mediation between labour and leisure time, but it deprives workers of the social richness offered by workplaces. The free time, mainly for women, results in heavier household chores and parental care. The multiplying effect on employment generated by women's labour disappears with the drop of domestic duties overflowing to external workers. Working at home weakens the worker's unionised force and opens to remuneration mechanisms based on the produced value: the coming back of piece work,

Fig. 5 E-commerce, service requirements and environmental impact

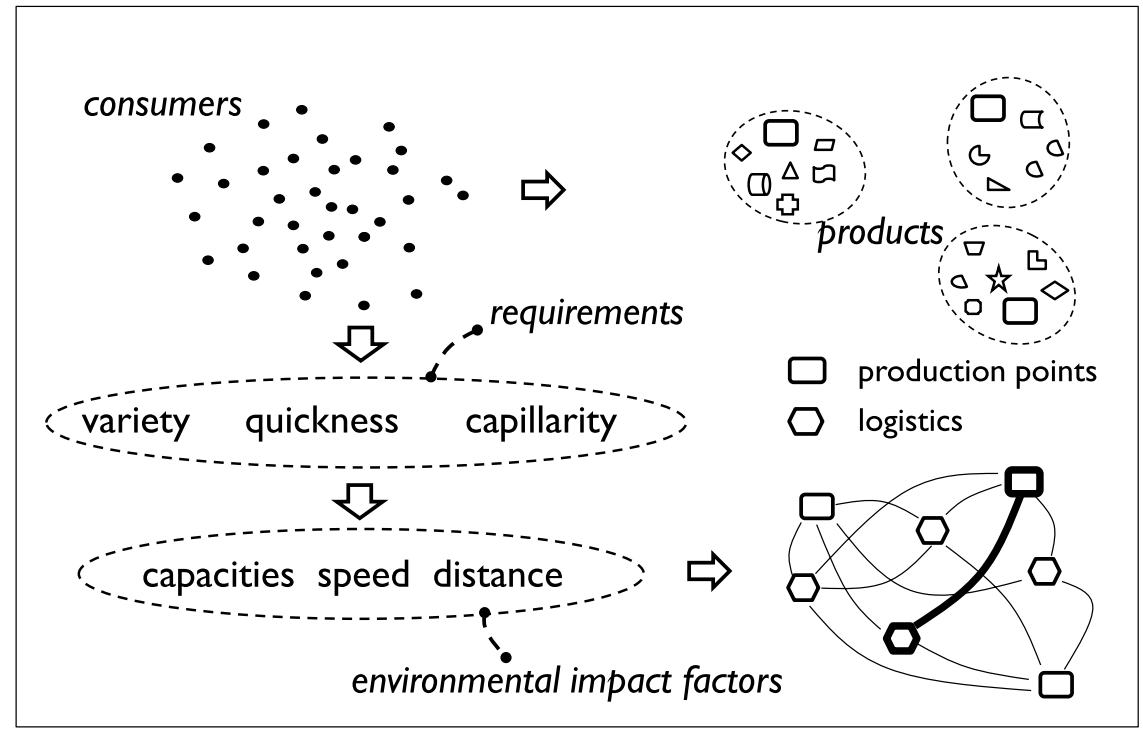


primarily for routine jobs. With the weakening of its collective dimension, the worker-firm relationship deviates towards an asymmetric, personal negotiation.

The eventuality that homework becomes a non-negligible phenomenon (see [50, p. 25-26]) should solicit political answers to overcome social limits and labour precariousness. Here are some hints that leverage the revival of minor centres.

The rise of decentralised work should exploit the coworking concept, introduced a few decades ago. The coworking centres gather workers whose jobs are partially or fully computerised by the relevant enterprises. This configuration can attract a portion of the productivity factors previously eradicated from the worker's living place. European statistics state that most urbanised regions produce a high GDP per capita [23, p. 179-182]. This performance bases on the residing population. Hence it is blown up by the value produced by commuters. Therefore, a drift of jobs towards peripheral areas could represent an economic and social rebalancing factor.

From a conceptual angle, the above example helps appreciate that the research of sustainable solutions can benefit from responsible interpretations of digital attributes. In the coworking case, the place independence of the connected digital devices. "I use these functions regardless of place" has been intentionally revolved to bond the same functions to the place: "I can use these functions where my community lives". This conceptual torsion exploits the generic character of digital techniques. Similar interpretative discontinuities hold about another digital attribute: the storage capacity, enabling a time-flexible use of data and functions.

The quick and irreversible transformation of society in a community of permanently connected humans is perhaps the most evident social discontinuity ascribable to the digital network. We can set aside the critical reading of this collective bulimia and notice that accessing global information and interacting remotely with others has become a natural habit. Just a few decades ago, the risk of cultural segregation had been one of the major obstacles to any place-based development policy, but now these risks are vanishing. Decentralisation does not threaten the faculty to "be in the world"; instead, it may encourage new cultural activities based on more finalised uses of the digital characters. The minor centres can be shielded from the less desirable destiny one can imagine: to fall into the trap of localism, the drop of linkages with the outside world and the cultural involution. It could even happen that the level of sociality and participation hopefully produced by the renaissance of peripheral areas could convey some remains of personal discernment in the ocean of network-enabled possibilities.

Whenever the innovation focuses on socially sensible processes, taking digitalisation as an objective per se leaves the choice in the hands of global actors who, legitimately, point to economic returns. Conversely, considering the digital assets as (powerful) instruments widens the horizon of the possible options and helps to distil the most coherent ones. The two mindsets lead respectively to conservative policies or reflexive and participatory plans based on democratic passages. In recent decades, the confusion between objectives and instruments has threatened the horizon and effectiveness of innovation choices, particularly about the sustainability dilemmas.

\section{The value of integration and concluding remarks}

The previous sections have highlighted some policy directions addressing the renaissance of sustainable minor centres. They focus on environmental purposes (e.g., the carbon footprint of goods' production, the level of energetic self-sufficiency) and social aims (e.g., environmental health, new labour opportunities, technological and ecological consciousness, informed participation). In the moral responsibility framework, the place quality contributes to safeguarding the physical and cultural conditions on which a desirable life can be conceived for present and future societies [8, ch.2, IV, 3-4]. This burden consists of identifying the "quality ingredients" and defining "how" the community intends to preserve them.

Let us look at the debate about the sustainability perspectives. The prevailing mindset rests on the belief that society's efforts in carbon footprint reduction, renewable sources, recycling, and reuse of materials will be sufficient to reach a sustainable future without substantially modifying our (Western) standard of life. This position gives full credit to technological developments and confirms the market's leading role in wellbeing creation. Here, the quality ingredients coincide with those matured through consolidated habits and how to proceed grounds mostly on rationalising efforts. GDP growth remains an objective, and the neoliberalist model as an impressive wealth generator is not challenged. Indubitably, the efforts to reduce the ecological impact of the current processes (decoupling) are moving in the right direction.

However, the bet at stake is so high that a more radical belief claims that limiting our action to improve the efficiency of existing processes is insufficient to guarantee sustainability conditions in the short time left. In line with this view, it is 
urgent to create some deviation from the current economic models and abandon the humans' presumption to extend their physical dominion on all the remains of the natural being. The deviation implies that new quality ingredients are addressed through transformative actions, as requested by the criticality of incumbent threats: a school of thought moved by ambitious principles and clear consciousness of our limits [21, p. 84-102, 51, 52].

The two positions are compatible, at least in the medium term, provided that the efforts to radically change the existing development models are given a concrete chance, and some strident claims are recognised and reported unanimously. Technological advances cannot absolve us from raping mountain creeks with our SUVs as long as moved by electrical engines. Nor from opening artic routes for hydrogen-powered ships transporting immeasurable quantities of goods between the continents or from relentlessly using growing amounts of energy, strictly green, that prodigal and boundless wind farms will offer us.

In this virtual debate, it is helpful to consider the positions of international organisms such as the IPCC [4] and the MIT [53]. According to their (providential) evaluations, the plans to reach the sustainability targets fixed for 2030, 2050, 2100 become more and more severe: an implicit acknowledgement of the limits of present measures. These limits are so evident that some observers argue that the time has come to certify the humans' inadequacy to avoid the announced disasters and shift towards pure adaptation policies [54].

Instead, these pages are inspired by the profound belief that it is possible to try additional routes because the social and cultural forces ready to experiment and adopt responsible behaviours are growing, even though timely political elaborations have not yet intercepted them. This spirit is active in cultural discourses, solidaristic actions, ecological movements and third sector initiatives. The point is to canalise this hidden pressure in new models and consolidate them once their environmental, social and economic sustainability is proved. The technological instruments and the social sensibilities are there.

The polarisation to minor centres offers the necessary ingredients to develop new practices: competitiveness and consumerism anxiety are relaxed, and new forms of sociality, based on cooperative and participatory principles, can find favourable conditions to develop. The anticipatory approach allows the community to prefigure new socioeconomic arrangements rather than being dragged by pure technicist and profit-based tactics.

Thanks to the spatial proximity, the functional complementarity and the commonality of intentions offered by minor centres, different policy directions can fertilise each other and magnify the total effect produced (positive correlation). For instance, both energy communities and circular economy create, independently, positive impacts in terms of energetic footprint and job opportunities. However, further advantages come from the circumstance that the $E C$-produced energy can cover the energy needs of circular tasks, while the latter can supply maintenance and control services to conduct the energy community devices. Fostering this cross-fertilisation is a challenging issue for the joint work of administrators, sociologists, territorial planners, economists and engineers in a transdisciplinary and collaborative effort.

Some social circumstances can reinforce the vivification of peripheral areas. Even young citizens with high professional positions are moving to rural or small towns, a coming-back often encouraged by family ties or simply due to the degradation of the cultural and social advantages the city has offered until now (urban paradox [23, p. 34-36]). The emerging models for a healthy life, including disease-prevention habits, de-hospitalised care, and the systemic vision of human health (physical, cognitive and relational), represent a potential buster of the place economy. These conditions are not easy to realise in the city, where an individualistic spirit often prevails, and loneliness is becoming the principal affliction, primarily for aged persons. These opportunities can be captured to harmonise the city-country relation and rearrange the mobility process of humans and goods.

If sustainability policies cannot succeed but through a diffuse participatory and dialectical spirit [55], local communities should be well-positioned to revive the democratic process. The local character of problems connects the deliberative act with the declared intention and its impact [56]. Politics and local actors accept a two-fold responsibility: choosing the innovation option and creating a renewed democratic tension around it.

The proposed model erodes some parts of the current economic processes (the efficiency economy) and moves them to the social cohesion dimension, where sustainability aims are more likely to be achieved [57, p. 17-36]. In general, the two kinds of economy can coexist, even if they ground on radically different principles. For instance, the progression of non-tradable outputs may result locally in weak economic growth. However, what many people are experiencing now is the forced shift from employment to subsidised unemployment conditions, while the renaissance of minor centres could offer beneficial osmosis between different kinds of jobs, possibly in different professional stages of the worker. Appropriate social policies may still guarantee solid prosperity in the developed world [18], even in economic slowdowns. Several 
attempts to realise new forms of local development are in progress [58], also through new forms of entrepreneurship revitalising the less innovative areas [59].

It is helpful to remind that we all spend most of our time in the local dimension, possibly in different life phases. There is strong evidence of the attraction of minor centres towards persons of different cultures and sensibilities, maybe unevenly, with an intensity tied to different seasons of the human experience. The article is simply a stimulus to explore with new eyes the feasibility of a model that tries to connect the individual consciousness and the collective behaviour, to build on the biological richness and the cultural values of peripheral areas, to revive the hope for inclusive and sustainable development and new forms of dignified labour.

Authors' contributions All the manuscript has been written by Giovanni Colombo All the figures have been conceived and drawn in PowerPoint by Giovanni Colombo. The author read and approved the final manuscript.

Data availability Data sharing not applicable to this article as no data set were generated or analysed during the current study. Data mentioned in the article are extracted from documents suitably reported in the references with the regular hyperlink for access.

\section{Declarations}

Competing interests The authors declare no competing interests.

Open Access This article is licensed under a Creative Commons Attribution 4.0 International License, which permits use, sharing, adaptation, distribution and reproduction in any medium or format, as long as you give appropriate credit to the original author(s) and the source, provide a link to the Creative Commons licence, and indicate if changes were made. The images or other third party material in this article are included in the article's Creative Commons licence, unless indicated otherwise in a credit line to the material. If material is not included in the article's Creative Commons licence and your intended use is not permitted by statutory regulation or exceeds the permitted use, you will need to obtain permission directly from the copyright holder. To view a copy of this licence, visit http://creativecommons.org/licenses/by/4.0/.

\section{References}

1. United Nations. Transforming our World: the 2030 Agenda for Sustainable Development. Dept. of Economic and Social Affairs. 2015. https://populationmatters.org/sites/default/files/Hitting\%20the\%20Targets\%20-\%20Population\%20and\%20the\%20SDGs.pdf.

2. IEEP Institute for European Environmental Policies. The 2020 European Sustainable Development Report: Meeting the SDGs in the face of COVID-19 pandemic. 2020. https://s3.amazonaws.com/sustainabledevelopment.report/2020/europe_sustainable_development_ report_2020.pdf

3. EU Council. Next Generation EU (Recovery and Resilience Facility; React EU). 2020 https://www.consilium.europa.eu/media/45109/210720euco-final-conclusions-en.pdf.

4. IPCC Intergovernmental Panel on Climate Change Special Report on Global Warming of $1.5^{\circ} \mathrm{C} .2018$. https://www.ipcc.ch/sr15/.

5. World Inequality Lab. World Inequality Report 2018. Paris School of Economics. 2018. https://wir2018.wid.world/files/download/wir20 18-full-report-english.pdf.

6. Fuentes-Nieva, R. Working for the few - Political capture and economic inequality Oxfam International. 2014. https://oi-files-d8-prod.s3. eu-west-2.amazonaws.com/s3fs-public/file_attachments/bp-working-for-few-political-capture-economic-inequality-200114-en_3.pdf.

7. Islam, S.N. Inequalities and Environmental Sustainability. UN-Department of Economic \& Social Affairs Working Paper. 2015. https://www. un.org/sites/un2.un.org/files/1597341726.2653.pdf.

8. Jonas, H. Das Prinzip Verantwortung (1979). Italian translation: II principio responsabilità. Einaudi Paperbacks Filosofia, 1993.

9. Rolston III, H. A new environmental ethics - the new millennium for life on the earth. Second Edition - Routledge. 2020.

10. Rolston III, H. From beauty to duty: aesthetics of nature and environmental ethics. In: Environment and the arts: perspectives on environmental aesthetics. Arnold Berleant ed. 2002. https://is.muni.cz/el/fss/jaro2014/HEN580/um/48946649/Rolston-III-beauty-to-duty.pdf.

11. Weber M. The spirit of work and vocation - Second lecture: politics and vocation. Verlag Dunker\&Humboldt (1919). In: "Weber's Rationalism and Modern Society", edited and translated by Tony Waters, Dagmar Waters - 2015. https://www.palgrave.com/gp/book/9781137373 533.

12. Owen R, Pansera M. Responsible innovation and responsible research and innovation. Handbook od Science and Public Policy, Edited by D. Simon, S. Kuhlmann, J. Stamm, W. Canzler. 2019, 26-48. https://www.elgaronline.com/view/edcoll/9781784715939/9781784715939. 00010.xml?utm_campaign=JPE14808\&utm_medium $=$ cms\&utm_source=CPB.

13. de Saille S. Innovating innovation policy: the emergence of responsible research and innovation. J Respons Innov. 2015. https://doi.org/ 10.1080/23299460.2015.1045280.

14. Stilgoe J, Owen R, Macnaghten P. Developing a framework for responsible innovation. Res Policy. 2013;42:1568-80. https://doi.org/10. 1016/j.respol.2013.05.008. 
15. Luetz J. Climate change and migration in the Maldives: some lessons for policy makers. - Climate Change in Pacific Countries Walter Leal Filho editor - Springer. 2017. https://www.springerprofessional.de/en/climate-change-and-migration-in-the-maldives-some-lesso ns-for-po/12050266.

16. Wiedman T, Lenzen M, Keyßer LT, Steinberger JK. Scientist' warning on Affluence. Nat Commun. 2020;11:3107.

17. Diercks G, Larsen H, Steward F. Transformative innovation policy: addressing variety in emerging policy paradigms. Res Policy. 2019. https://doi.org/10.1016/j.respol.2018.10.028.

18. Jackson, T. Prosperity without growth. Foundation for the Economy of Tomorrow, Second edition. (2017).

19. Bel G, Teixidó JJ. The political economy of the Paris Agreement. Income inequality and Climate Policy. UBIREA Research Institute of Applied Economics. 2019. https://ideas.repec.org/s/ira/wpaper.html.

20. Lorek S, Spangenberg JH. Sustainable consumption within a sustainable economy-beyond green growth and green economy. J Cleaner Prod. 2014;63:33-44.

21. Jackson T, Victor PA. Does slow growth lead to rising inequality? Some theoretical reflections and experimental simulations. Ecol Econ. 2015. https://doi.org/10.1016/j.ecolecon.2015.03.019.

22. Piketty, T. Capital in the 21 st Century. Harvard University Press, Cambridge Mass. (2014). Italian Translation: II Capitale del $21^{\circ}$ Secolo. Bompiani. 2014.

23. Eurostat. Urban Europe, Statistics on Cities, Towns and Suburbs. 2016 edition. (2016). https://ec.europa.eu/eurostat/documents/32174 94/7596823/KS-01-16-691-EN-N.pdf/0abf140c-ccc7-4a7f-b236-682effcde10f?t=1472645220000.

24. Barca F, Luongo P. Un futuro più giusto. Rabbia, conflitto e giustizia sociale, II Mulino, (A more just future. Rabies, conflict and social fairness). 2020.

25. Newman P. Decoupling economic growth from fossil fuels. Modern Econ. 2017;8(6). https://espace.curtin.edu.au/bitstream/handle/20. 500.11937/64701/263473.pdf?sequence $=2$

26. Meinrenken CJ, Chen D, Esparza RA, lyer V, Paradis SP, Prasad A, Whillas E. Carbon emissions embodied in the product value chains and the role of LCA in curbing them. Nat Sci Rep. 2020;10:1-2.

27. European Commission. European Semester: Assessment of progress on structural reforms, prevention and correction of macroeconomic imbalances, and results of in-depth reviews COM 150 final. 2020. https://ec.europa.eu/transparency/regdoc/rep/1/2020/IT/ COM-2020-150-F1-IT-MAIN-PART-1.PDF.

28. Workman F, Berman J, Thomas C. Environmental impacts of renewable energy. The University of Vermont - The Vermont Legislative Research Service. (2016). https://www.uvm.edu/sites/default/files/Department-of-Political-Science/vlrs/Environment/Environmen tal_Impacts_of_Renewable_Energy.pdf.

29. European Union. Directive 2018/2001 on the promotion of the use of energy from renewable sources. (2018). https://eur-lex.europa. eu/legalcontent/EN/TXT/PDF/?uri=CELEX:32018L2001\&from $=\mathrm{fr}$

30. Caramizaru A, Vihlein A. Energy communities: an overview of energy and social innovation. JRC Science for Policy Report. (2020) http://publications.jrc.ec.europa.eu/repository/bitstream/JRC119433/energy_communities_report_final.pdf

31. Colombo G, Ferrero F, Pirani G, Vesco A. Planning local energy communities to develop low carbon urban and suburban areas. Energyton. 2014

32. Font Vivanco D, McDowall W, Freire Gonzalez J, Kemp R, van der Voet E. The foundation of the environmental rebound effect and its contribution towards a general framework. Ecol Econ. 2016;125(C). https://www.researchgate.net/publication/298334148_The_ foundations_of_the_environmental_rebound_effect_and_its_contribution_towards_a_general_framework

33. Hewitt RJ, et al. Social innovation in community energy in Europe: a review of the evidence. Front Energy Res. 2019;7:31. https://doi. org/10.3389/fenrg.2019.00031/full.

34. Lowitzsch J, Hoicka CE, Tulder FJ. Renewable energy communities under the 2019 European Clean Package - Governance model for the energy clusters of the future? Renew Sustain Energy Rev. 2020. https://doi.org/10.1016/j.rser.2019.109489.

35. MacArthur Ellen Foundation, SUN, McKinsey Centre for Business and Environment. Growth Within: A Circular Economy Vision for a Competitive Europe. (2015). https://www.ellenmacarthurfoundation.org/assets/downloads/publications/EllenMacArthurFounda tion_Growth-Within_July15.pdf.

36. Llorente-Gonzáles LJ, Vence X. Decoupling or Decaffing? The underlying conceptualisation of Circular Economy in the European Union Monitoring Framework. Sustainability. 2019. 11 https://www.mdpi.com/2071-1050/11/18/4898/htm

37. European Commission. A monitoring framework for circular economy. COM 29 final. (2018). https://ec.europa.eu/transparency/ regdoc/rep/1/2018/IT/COM-2018-29-F1-IT-MAIN-PART-1.PDF.

38. European Commission. A new Action Plan for a cleaner and more competitive Europe. COM 98 final. (2020). https://eur-lex.europa. eu/resource.html?uri=cellar:9903b325-6388-11ea-b735-01aa75ed71a1.0020.02/DOC_2\&format=PDF.

39. Frocrain P, Giraud P-N. The evolution of tradable and non-tradable employment: evidence from France. Centre for industrial economics, i3UMR, CNRS. Working Paper. (2017). https://hal.archives-ouvertes.fr/hal-01981428/document.

40. Stiglitz JE. Rewriting the rules of the European Economy. Foundation for the European Progressive Studies. 2018.

41. European Commission. Working with Parliament and Council to make the CAP reform fit for the Europe Green Deal. 2020. https://ec. europa.eu/info/sites/info/files/food-farming-fisheries/key_policies/documents/factsheet-cap-reform-to-fit-european-green-deal_ en.pdf.

42. EC-6 European Commission. Bringing nature back into our lives. COM 380 final. 2020. https://ec.europa.eu/info/sites/info/files/commu nication-annex-eu-biodiversity-strategy-2030_en.pdf.

43. Smith P. Soil Carbon Sequestration and Biochar as Negative Emission Technologies. Global change biology. Wiley Online Library. 2016. https://aura.abdn.ac.uk/bitstream/handle/2164/8270/Smith_Soils_Biochar_NETs_tables_figures_embedded_final.pdf?seque nce $=1$.

44. Frank S, et al. Reducing greenhouse gas emissions in agriculture without compromising food security? Environ Res Lett. 2017;12:105004. https://doi.org/10.1088/1748-9326/aa8c83/pdf.

45. Chiti T, Blasi E, Pellis G, Perugini L, Chiriaco MV, Valentini R. Soil organic carbon pool's contribution to climate change mitigation on marginal land of a Mediterranean montane area in Italy. J Environ Manag. 2018;18:593-601. https://doi.org/10.1016/j.jenvman.2018.04.093. 
46. Frey CB, Osborne MA. The future of employment: How susceptible are jobs to computerisation?. Technol Forecast Soc Change. 2017;114: 254-80.

47. Camilleri MA. Closing the loop for resource efficiency, sustainable consumption and production: a critical review of the circular economy. Int J Sustain Dev. 2018;21:1-4.

48. Tukker A. Product services for a resource-efficient and circular economy. J Cleaner Prod. 2015;97:76-91. https://doi.org/10.1016/j.jclep ro.2013.11.049.

49. Shahmohammadi S, Steinmann ZJN, Tambjerg L, van Loon P, King JMH, Huijbregts MAJ. Comparative greenhouse gas footprint of on-line versus traditional shopping for fast-moving consumer goods: a stochastic approach. Environ Sci Technol. 2020. https://doi.org/10.1021/ acs.est.9b06252.

50. Fana M, Tolan S, Torrejón S, Urzi Brancati C, Fernández-Macías E. The COVID Confinement measures and EU Labour markets. JRC Technical Report. (2020). https://publications.jrc.ec.europa.eu/repository/bitstream/JRC120578/jrc120578_report_covid_confinement_measures_ final_updated_good.pdf

51. Victor, P.A. Growth, Degrowth and Climate change: a scenario analysis. Ecological Economics. 2011. http://www.greeninstitute.gr/wpcontent/uploads/2013/02/Victor_Growth-Degrowth-and-Climate-Change.pdf

52. Tartaglia A. Growth and inequality in a physicist's view. Biophysical Econ Sustain. 2020;5:8.

53. MIT. Food, Water, Energy, Climate. Outlook Perspectives from 2018. Joint Programme on the Science and Policy of the Global Change. 2018. https://globalchange.mit.edu/sites/default/files/newsletters/files/2018-JP-Outlook.pdf.

54. Franzen, J. What if we stopped pretending? The New Yorker - Cultural Comment. 2019. https://www.newyorker.com/culture/culturalcomment/what-if-we-stopped-pretending

55. Colombo G. The grand challenges: a potential boost for a responsible research and innovation. Sociol Anthropol. 2015;3(9):447-54.

56. van Oudheusden M. Where are politics in responsible innovation? J Respons Innov. 2014. https://doi.org/10.1080/23299460.2014.882097.

57. Barca F. An agenda for a reformed cohesion policy - a place-based approach to meeting the European Union challenges and expectations" Independent Report to the Commissioner for Regional Policy. 2009. http://ec.europa.eu/regional_policy/policy/future/barca_en. htm.

58. Inteligência em Inovação, Centro de Inovação. Creative-based strategies in small and medium-sized Cities: Guidelines for Local Authorities. Creative Clusters. 2011. https://urbact.eu/sites/default/files/import/Projects/Creative_Clusters/documents_media/URBACTCrea tiveClusters_TAP_INTELI_Final_01.pdf.

59. EIT European Institute of Innovation and Technology. Regional Innovation Scheme-Implementation Guidelines Note 2018-2020. (2017). https://eit.europa.eu/our-activities/eit-regional-1 innovation-scheme-ris

Publisher's Note Springer Nature remains neutral with regard to jurisdictional claims in published maps and institutional affiliations. 